Volume and Issues Obtainable at Center for Sustainability Research and Consultancy

Journal of Business and Social Review in Emerging Economies

ISSN: 2519-089X (E): 2519-0326

Volume 4: Issue 1June 2018

Journal homepage: www.publishing.globalcsrc.org/jbsee

\title{
Gwadar Port: As an Economic hub for Maritime Trade in the World Corridor (CPEC)
}

\author{
${ }^{1}$ Asmat Naz, ${ }^{2}$ Fatima Ali \\ ${ }^{1}$ Dean Faculty of Arts \& Social Sciences, The Women University Multan, Pakistan. drasmatnaz@wum.edu.pk \\ ${ }^{2}$ Lecturer, Deptt of History \& Pak Studies. The Women University Multan. \\ fatimawum@gmail.com
}

\begin{tabular}{|c|c|}
\hline ARTICLE DETAILS & \multirow{8}{*}{$\begin{array}{l}\text { Gwadar port, deep-sea port, is used and operated as a mean to serve the } \\
\text { supply and import requirements of a well prominent hinterland, as other } \\
\text { harbors of Pakistan has been working. Gwadar port is situated in the } \\
\text { Arabian Sea, at Gwadar in Baluchistan province of Pakistan. The economic } \\
\text { prediction of Gwadar port is the trump card for economy and trade routes } \\
\text { for Central Asian States and the world, which holding trade from the } \\
\text { western part of China and assume as reasonable interchange transshipment } \\
\text { to another desire ports of the region. The port features prominently in the } \\
\text { China-Pakistan Economic Corridor (CPEC) plan, and is considered to be a } \\
\text { crucial link between the ambitious One Belt, One Road and Maritime Silk } \\
\text { Road projects. The proposed paper through the empirical and inductive } \\
\text { research approach tries to identify the importance of Gwadar port in the } \\
\text { economic and maritime trade of in the world. Gwadar port has an eminent } \\
\text { status in the trade of China and Pakistan throughout the world. In future, it } \\
\text { will be a keystone in the economic development of Baluchistan as well as } \\
\text { Pakistan. Furthermore, China is also investing in the development of } \\
\text { Gwadar port to make it the center of maritime trade of Chinese products. } \\
\text { Thus, in a short span it becomes a center of maritime trade of the world. }\end{array}$} \\
\hline History & \\
\hline d form & \\
\hline Available Online: & \\
\hline Keywords & \\
\hline $\begin{array}{l}\text { Gwader Port, Maritime Trade, } \\
\text { CPEC. }\end{array}$ & \\
\hline $\begin{array}{l}\text { JEL Classification: } \\
\text { N10. }\end{array}$ & \\
\hline & \\
\hline
\end{tabular}

(c) 2018 The authors, under a Creative Commons Attribution-

NonCommercial 4.0

Corresponding author's email address: drasmatnaz@ wum.edu.pk

Recommended citation: Naz, A., Ali, F. (2018). CGwadar Port: As an Economic hub for Maritime Trade in the World Journal of Business and Social Review in Emerging Economies, 4(1) 7-16

DOI: $10.26710 /$ jbsee.v4i1.352

\section{Introduction}

Geographically, Gwadar covers by Awaran and Kech district in North, in east surrounded by Lasbela and south barriers by water bodies of Arabian Sea and Iran lies in its west. Gwadar district consists of 12637 square kilometers, including Pasni. This area also has a great geopolitical importance as its location presents the adjacent valuable oil trade route like the Strait of Hormuz and economically rich areas of the Middle East.

Basically, the warm water third deep sea port of Pakistan, Gwadar port located at the apex of Persian Gulf (PG) which is rich with oil. It provides a sea route for all Asian regions for their trade and also a way of economizing trade for Central Asian countries. Gwadar port remained as a part of Oman rather than Pakistan. On 8th September 1958 it took from the control of Oman as it enclave in Pakistan. In 1964, it was decided by the government that a port at Gwadar should built but it deprived of the proper attention 
of the government. It became the part of Baluchistan in 1 July, 1977 according to the official record, and its construction also continued. So, Fish harbor successfully completed in back year 1992 in other side, a great project of Gwadar development as a deep sea port has been projected with the technical assistance of China in June, 2002 and phase -I of the port had been constructed in 2004. In 2015, it was decided by the government of Pakistan that the Gwadar port will develop under the CPEC project. So, in 2016, it was given to China on lease for forty three years, till $2059 .{ }^{i}$

The important feature of the hub is its economic and strategic location, which considers a main source of maritime trade. In spite of regional significance, as hub port, it is capable to retrieve large ships, security of terminal facilities, sharpness for container handling mechanism, has quick serve ability for ships in limited geographical premises and reasonable cargo handling charges and terminal for large transshipment which should fast and easy to use. It is equipped with optimum number of cranes, sufficient container for handling, storage capacity and modern technology built in computer network system to run the whole port terminal. The progress of the port may examine by its working condition as the loading and unloading of ships which arrived the harbor, departure or arrival of cargo in and out of the harbor and mass storage capacity for cargo within port premises. ${ }^{\text {ii }}$

The prominent and noticeable outcome of hub is the production of income through transshipment, cargo and container facilitation. Another important factor of the hub is to promote indigenous importers and exporter for an alien access to other side market of sea lane. This kind of services will reduce the transportation expenditure.

The coastal area of Gwadar is $600 \mathrm{~km}$ long comprised sandy shores and bays. In the past, small town Gwadar was known as fishing point, a side by Makran shore is going to be developed which accomplishes the attention of strategic significant regions:

- Middle East which laden with Oil

- Huge populated area of South Asia

- Packed with resources of Central Asian Countries. iii

According to the analysts, the contribution of China for the development of Gwadar port will be a blessing for the people of this region and for Pakistan as well. A highway road of ECO, Coastal motorway and other relevant big projects of the road network will connect Gwadar Port through north side situated countries, the Gulf regions, Chinese border and other rest of the world. Government of Pakistan in year 2007 officially offered the construction and operations of this port to The Port Singapore Authority (PSA) for 25 years. It can say that the development of the port is a milestone of mega Gwadar plan for the future of Pakistan. This plan directly carried out by the GDA (Gwadar Development Authority) which comprises road network tendency towards Gwadar from Karachi, Omara, Pasni, Turbat and other sides will be completed in four different stages. 


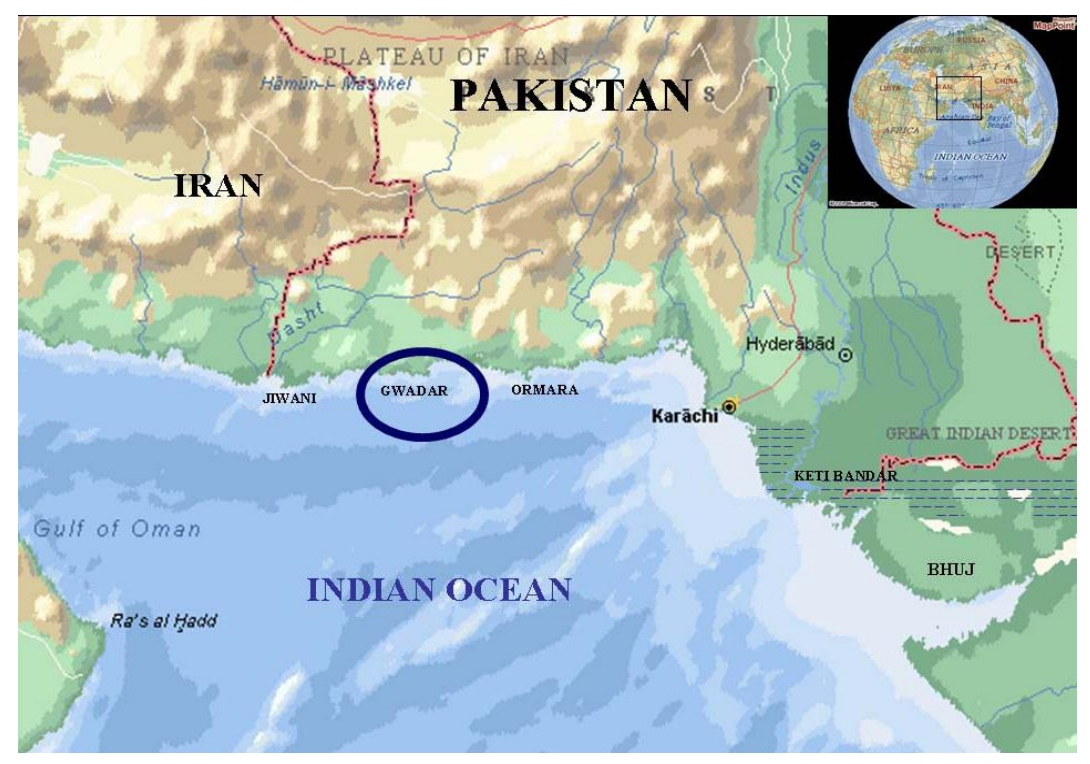

Gwadar Port ${ }^{\text {iv }}$

\section{Objectives of Gwadar port development:}

The port of Gwadar is situated on the main stream of economy through which Pakistan can make a hold on the maritime trade with Iran and other Middle Eastern areas. There has explained some objectives related to the development of the port and its benefits for the people. The Gwadar port may use as

- The great shipping hub to provide facilities for all kinds of ships and all sizes of cargo category handling.

- To improve in the trade lane for economic uplift and industry on the domestic level and the entire region.

- To work as speedily that is proficient, successful, aggressive and transparent fair.

- Always remain attached and ready for expectations of local level and internationally and concern stakeholders

\section{A linkage of CPEC and Gwadar port:}

Pakistan and China as all weather strategic partners have a history of glorious friendly relations. Both countries always try to make strong relations through different geo-political, strategic and economic projects/agreements. The China-Pakistan Economic Corridor (CPEC) is also a key to make strong economic relations of both countries. It is considered to be an extension of China's proposed $21^{\text {st }}$ century

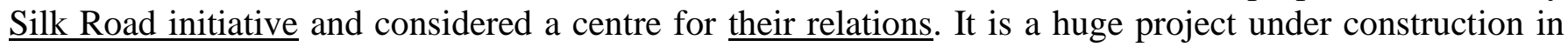
different phases that will undertake the construction of highway and railway links running through the areas from Gwadar in Baluchistan and culminating in Kashgar in western China, while passing through various regions of Baluchistan, Sindh, Punjab, Khyber Pakhtunkhwa (KPK) and Gilgit-Baltistan (Khunjrab Pass). It will connect Pakistan with China and the Central Asian countries by the highway connecting Kashgar to Khunjrab and Gwadar. The CPEC is of high significance, as it making this region economically more viable, stable and sustainable. It is also one of many mega projects planned by China in Central, South and South East Asia for expanding its political and economic influence to counter the US influence in the region. China has made an attempt to fulfill multiple interests of its own by the financial investments in region on CPEC. It shall act as a trade bridge between China, Middle East and Europe through Pakistan and proved a source of economic benefits. Furthermore, Gwadar seaport has been handed over to China to develop it and also to look after in other related projects (rail and road networks, industrial infrastructure) including CPEC. So, the Chinese Company is handling at the port of Gwadar to activate it as a trade center in the Indian Ocean. China can play a vital and leading role for active competitor in this region and can try best to make necessary arrangement for long term naval military presence in this scenario. In this rushed environment, Pakistan's interests in the economy in this deep sea warm water port is might be compromised. 


\section{Status of Gwadar port in the Contemporary ports:}

There is already working many parallel ports to Gwadar port, but the Gwadar port considered more because of its location and significance. Following are the main ports considered more significance because of the economic and trade activities.

- Dubai port is one of most prominent port parallel to Gwadar port. Dubai development authority is controlling two valuable ports, Rashid and Jabel Ali ports. The Rashid sea port established as the state of the art, according to its design and working capacity in the huge Gulf consumer market. Dubai Port Authority facilitates and successfully handling near about 2.8 million TEU per year there $25 \%$ transshipment within the Gulf area. Another port Jebel Ali enhances the performance of Dubai authority and meets 5.7 million TEU annually. ${ }^{\mathrm{v}}$

- The Salalah port (Oman) used as the center of trade to Pakistan and India. However, the port is keeping a hole to handle with the cargos and trade containers. This terminal was established in 1998 to deal with the terminals. However, it is more suitable for the Gwadar port to stop cargo entering to Dubai and Colombo harbors. So far as, the Hill wood Strategic Services, an American firm have drawn some plans of trade by Red Sea in 2002, when the major port is estimated at 1.2 million TEUs. ${ }^{\text {vi }}$ The port can contain vessels up to $16 \mathrm{~m}$ draft. The turbulent political situation of the Middle East is threatening to undermine its plan to snare more regional transshipment business. Its plan to set up a 6,000 acre free trade zone hit a major snag in 2002, when the major investor, Hill wood Strategic Services, an American firm, withdrew from the venture on the eve of signing an agreement with the government, may due to geopolitical reasons. ${ }^{\text {vii }}$

- The ports of Iran (Chahbahar and Bandar-Abbas) have an international standard and considered as the main hub of Asian trade. The port of Bandar Abbas (Shahid Rajaee) consisting 24 Berths with 2 oil Berths. Moreover, its loom canal stretches on the area of $76.4 \mathrm{~km}$ and its depth is 13 meters. Yet, its only four berths have the capacity to handle vessels more than 100,000 DWT. It is trying by the Iranian government to increase 2.6 million capacities of the TEU. Another port of Iran called Chahbahar is having two landing pier, which may handle just 5 vessels to 25,000 awful shipping and check of 11 meters.

- The Port of Shuwaikh is a most dreadful port of Kuwait, situated in the Persian Gulf. It has a power station and a water desalinization plant in Kuwait. The port also has deep berths and handles cargo ships, fishery containers and passenger vessels. The port is being near about 800 acres on land and 300 acres of water. The Port of Shuaiba is another main port of the country. It is a well established industrial centre, has an oil refinery, a petrochemical plant and a seafood packing plant. It also has a great seawater desalinization plant in the world. The port was made as praise for the industry, which handles raw materials and various other kinds of cargoes. These prots are handled by the Kuwaiti Port Authority.

- The name of this port is Mina Sulman (Bahrain), which is medium in size and an important harbor of Bahrain. It is situated in Manama. It is covering almost 250 acres with 600 meters long berths, as 80 percent of cargo is based on container. Port Sitra is probably a smaller port of the country.

- This harbor is situated in the Ras Laffan area in Qatar, having an oil industry. The port is having a capacity to deal with the transportation. It has the biggest liquidized natural gas export facility in the world, over 2100 acres. The Port of Doha is another medium sized port, while the smaller one is the other regional ports.

- Karachi port is an important place in the country is having many berths, $12 \mathrm{~km}$ extensive canals and 13 meter scour (earth removes), dealt with a number of cargoes. According to the statistics it manages almost 14 million tons liquid and 12 million tons dry consignments. On the other side, the Port Qasim is simply stretching in the east at the length of $156 \mathrm{~km}$ from Karachi. It is also considered as a part or extension of the Karachi sea port. The Qasim harbour having $45 \mathrm{~km}$ long strait and $12 \mathrm{~m}$ scour. It has fewer facilities as comparable to the Karachi port, as it has 30 berths with 3 oil support beam for landing ships, while Qasim harbor has just 7 berths which use for many directions. Additionally, the port of Karachi is also considered as a gateway for Asia 
because of its important geographical and strategic location. Annually, these ports are having the range of 25 and 17 million ton trade respectively. viii

The narrow band and capacity of internal ports of the region will be a consequence of the prosperity of Gwadar warm water Seaport as a hub harbor and it could attract new and great traders or investors to come for trade in Pakistan. ${ }^{\text {ix }}$ However, the establishment of this port is may also cause an antagonism in the region with Middle Eastern Countries because it will share the trading markets. Whereas, the suitable solid policies and priorities of government can be decided the future and economic contribution of the port in the region.

\section{Gwadar as maritime port:}

It could say and do hope that the Gwadar port may provide an economic facility to the people of Pakistan and also work as a gateway for the country to the Republics of Central Asia including Afghanistan. In future, this mega project will provide facilities and economic reimbursement to the Central Asia, South Asia, China and Middle East. Moreover, this seaport will effectively serve for transshipment, warehousing, sea trade, to the management of commercial and industrial level accommodate for alien import and export trade, particularly with Afghanistan, Oman, United Arab Emirates, Saudi Arabia, Qatar, China and Central Asian Republics. These countries may find the safe, efficient and the short trade route through the Gwadar port and supply their commodities in all over the world. Gwadar port because of its valuable geographic location and at the apex of Arabian Sea is a more suitable route on lowest cost and shortest way for transportation to South, Central and West Asian countries.

Consequently, the harbor will highly contribute in the progress of national and international trade arenas. Moreover, the port of Gwadar will be a competitive place as of Dubai (UAE) and Salalah (Oman) harbors and may also supply the natural oil and mines of Central Asian states. For the international trade, the government is trying to develop it on the patterns of other neighbouring ports like Bandar Abbas and Chahbahar (Iran). Simultaneously, a capacity of import-export of goods is too increasing in Gwadar warm water seaport to fulfill the requirements of great ships and to increase its regional significance in the world. ${ }^{\mathrm{x}}$ Thus, the port works as a hub that can collect and handle trade in abundant numbers from one concentrated point ${ }^{\mathrm{xi}}$ because trade play a vital role in a quantitative manner and economic development of the state and its nation. ${ }^{\text {xii }}$

\section{The Economic prospects of Gwadar port:}

Conventionally, the port of Gwadar is playing an important role in the progress of the economy of Pakistan. Yet, the heavy trade has been predicable after the construction of industries in Gwadar and near regions. The government of Pakistan is making a scheme to consider it an export processing and tax free area to attract the investors. This step has been taken by the government to flourish the trade and economy of the state. Furthermore, the coastal roads can supply a huge volume of trade from different areas of the country by the port of Baluchistan. However, other ports of Pakistan are already working for the economic development and domestic trade.

It suggests that the country should take a step to construct the port of Gwadar by the predictable needs of business and investment, expanding desires of maritime harbors and most prominently the exchange desire of natural sources of the world. Moreover, the port of Gwadar has been made to deal with the local cargo and maritime harbor to attract the investors and to invest in the country and also introduced advance technology as well as provide chances of employment to the natives. The maritime export of goods by the seaport will increase the national income of Pakistan like other ports as Hong Kong contributed over $20 \%$ of total 161.5 Billion Dollar GDP of the country in the last year and trade in Dubai is $16.5 \%$ of the total economy of 20 billion. ${ }^{\text {xiii }}$ The work on another project of 'Trans Afghan Gas pipeline' has been started and $1400 \mathrm{~km}$ long pipeline passes through Turkmenistan, Afghanistan and different areas of Pakistan including Gwadar. It is hoped that the gas will also provide to the global markets at the completion of the scheme. 


\section{Gwadar port: a trade center of China:}

Almost all countries of the continent Asia, including China, are important because of their geographical positions. It is considered as a hub of economy and trade in the world. The basic objective of the construction of this port is to increase the transportation and trade links of Pakistan with China. The Eastern side of China is more highly developed rather than the western side. In the past, China generated and prepared the Western prosperity scheme, but the western area stressed the consideration of Eastern region because of its cheaper labour power, natural sources and high rank markets. Geographically, Xinjiang province is $4500 \mathrm{~km}$ from the harbor of China, present on the eastern side but at the distance of $2500 \mathrm{~km}$ from the harbor of Gwadar.

The port of Gwadar will provide an ideal opportunity to China for its transshipment. Therefore, in future it will become an essential part of the external or world trade of China. The Karakoram highway has been already a joining point which connects China with Pakistan. Thus, the development of this highway and establishment of new roads will provide new links in both countries to make easy supply and transfer of their goods for their economic progress. The government is intending to make roads from Ratodero to Khuzdar for the links of Gwadar and Western China.

\section{Impacts on the economy of Pakistan:}

The fascinating key role of ports in the economy of any nation is discussed to highlight the importance sea trade routes. The current economic situation in Pakistan is a dependant and strong emphasis on the role of maritime and coastal elements. Gwadar port as compared to other parallel transshipment ports is more in capacity of transportation and infrastructure. The economic prediction of Gwadar port is the trump card for economy and trade passages for Central Asian States and the world.

Mainly, the competition starts among the countries on the seaport trade, which also impress by the availability and capacity of sources as funds to increase the economic development. However, the Governments finance and spend huge funds on the harbors for the economic development of the nations and states. Pakistan is also spending huge funds for the development of the port of Gwadar to make it an important economic and trading source of the region, although two ports of Karachi and Bin Qasim are already working and contributing to the economic development. However, a serious attention has also been given for the completion of third port of Pakistan, which in future will be a great source of economic stability of the nation.

In the future, there will increase the maritime and defensive strategies but the main projectors and statesmen should contribute to these plans. Their contribution can increase the investment through the investors and an easy access of people to the commodities and economic development. No doubt century of globalization, made so exponential trade through the sea level. ${ }^{\text {xiv }}$

No doubt, the Gwadar port will provide an easy access channel to warm water seaport. Simultaneously, it will have an attraction point for shipping companies moving cargo to and from landlocked states. By observing the current development in Baluchistan, which is a strategic location in the area of huge geopolitical significance. The establishment of Gwadar port is increasing its economic position and it has received the attention of the economic investors not only in Pakistan but also from all over the world. Some of the main countries are as Central Asia, Afghanistan, China, Japan, and Singapore keeping deep interest in the port significance and completion, because their economic interests are directly linked with the port.

The economic development of any country depends upon the development of ports with other sources of transpiration. The ports increase the value of any country and highly contribute to the economic development of it. Through the harbor there can supply and import all types of material including raw and well finish commodities. To some extent, it will be feasible for the regional economic development as the mineral sources of Asia not having any other suitable and short route except Gwadar. However, the modern world including Asian states cannot take such economic advantages from other ports as from 
Gwadar. With the other facilities and feasibilities, the Gwadar port mega project easily provides thousands of job opportunities for the native people in a short time. So, there is a need of proper work and provide opportunities for the people as the administrators and labours by establishing new projects. It has far accessed benefits in opposite to loans, abroad jobs and economic priorities. ${ }^{\mathrm{xv}}$

\section{Gwadar a special Economic Zone (SEZ)}

It is suggested and arguing that in order to accommodate fast commercial and economic innovation of the region. Gwadar will make a special economic zone for a specific period. The Special Economic Zone is certainly to cover the Gwadar city and industrial infrastructure currently under the plan and foreseen. Additionally, it is necessary to introduce some special offers for the economic stability of this region. A specific-incentives regime has been introduced. It includes the general tax capacity and liberal facilities pertaining to corporate ownership and integration of alien. The main object of this idea is to boost economic growth and investment in general particularly alien and indigenous side. This flow will attract industrial development and port activities throughput demands. It would clearly ensure the high contribution to increase the employment opportunities and socio-economic development of the province.

The Gwadar region and its port have Geo-strategic and political significance in the region, because of many important aspects. It is on the way of an important commercial area of the world. The oil rich region of the Middle East, Central Asia laden with natural resource and massive populate area of South Asia have great capabilities for growth in this $21^{\text {st }}$ Century. These regions are also important because of their economic and geography. The city of Pakistan, Gwadar has accomplished in global prominence sooner than the predictions of more analysis because it seems difficult that this region will get progress. Now, the new economic epicenter are revolves around Gwadar because of its economic importance and transportation. The port considers as an epicenter, which has all natural tendencies and the potential of converging the dream into reality.

Those who have future vision and interest seeing from a distance and understand the capabilities of Gwadar better than remaining close it and those who consider the Gwadar as a fishing village and do not recognize and appreciate the coming dynamics of a changing world and real positions are unfavourable for themselves and for the state. The researchers argued that through the development of Gwadar port, Pakistan can make strong its economy and may enter in the list of developed countries of the world.

In fact, Pakistan has neither a lack of human assets nor deficiency of Geo-economic, geopolitical and Geo-strategic potential. May be, we aren't having the regime of will and sincerity of goals and objectives to actualize our stated target, consequently, to achieve our top priority national goals, need to develop a strategy that would essentially demand hiring, harmonizing and successful services and expertise of both national and global concerned people within the state. The economic development of the region and different countries as India is possible through the indulgence and communication of China through the Port of Gwadar. However, there is also need of new harbors and maritime shipment routes in the Middle East and other world. ${ }^{\text {xvi }}$

\section{Government policies for foreign Investment:}

The multinational and international companies or investors are encouraged by the government through interest free trade that they come in Gwadar for the business and trade. The Government is increasing tax free trade for the industrial and multinational zones and companies. Therefore, in the area, it is also issuing an order for free economic investors to magnetize investments and trade volume at Gwadar. In the same way, few of the Gulf and Iranian ports were also promoted. The government also made a Concession Agreement (CA) of 40 years with the Port of Singapore Authority (PSA) that includes tax immunity. These initiatives have been taken on the same footings as new international trends in port operation would also be invaluable for the successful operation of the port. On the other side, a said export region nearest port of Gwadar for the internal and domestic regional investors also includes exemptions on customs, sales tax and excise duty. 


\section{Conclusion}

The economic contribution of the oceans has a great significance in the progress of human societies. Moreover, the economy is an integral part and parcel of national power and working like a key role to enhance the constancy of states. The Gwadar port development project is a long term mega plan of both countries (China and Pakistan). It will prove as an oasis for the major investors and production of thousand jobs. It certainly opens new trends of economic development in the coastal areas and towards accumulating of valuable revenues in the national economy. The Gwadar port will rise up to meet desired national economic requirement and share cargo handling capacity at existing ports. Additionally, other parallel development projects like, Makarn Coastal highway, Industrial zone, Saindak project also strengthens the port capability in economic affairs. The economic output, considerable political benefits can be accumulated through providing facilities at a seaport for other countries, especially to landlocked countries like Afghanistan. Gwadar port will have a capacity to handle huge flow of trade, besides of these all amenities and potential of the plot, but surly will face challenges and compete with all other parallel developed ports. Furthermore, this project directly will be beneficial for the people, who directly belong to this region. The importance of Baluchistan Province will also increase and the people could able to get progress and prosperity like other communities and people of Pakistan. In future, the port of Gwadar will become a developed and great harbor or an economic zone to fulfill the needs of South Asia, China, Afghanistan and Central Asia etc. With the passage of time, it will be beneficial for the development of the province and international trade of Pakistan. Yet, precise efforts are compulsory for developing, encouraging scenario for the industrial infrastructure in the region, which certainly based on good design strategy, program and scientific base access and positive direction to make it complete and competitive seaport mega project.

\section{References}

Ahmed, Hassan. (2006). Pakistan's Gwadar Port, prospects of Economic Revival, California: University Circle, Monterrey.

Ahmed, Iqbal, Syed. (1992). Baluchistan its strategic importance, Karachi: Royal Book Company.

Baloch, Khan, Muhammad, Sardar. (1977). History of Baloch Race and Balochistan, Quetta: Gosha-eAdab.

Barnett, Thomas P.M. (2002). Asia's Energy Future: The Military-Market Link, in Globalization and Maritime Power, edited by Tangredi, Sam J. Washington D.C.: National Defense University Press.

Bedi, Rahul. (September, 2000). India and China vie for regional supremacy, Jane's Intelligence Review. Chander, Parkash. (1990). International Relations, Delhi: Cosmos Book hive Pvt. Ltd.

Coulter, Daniel Y. (2002). The Rise of Hub Ports: in Globalization and Maritime Power, edited by Tangredi, Sam J. Washington D.C.: National Defense University Press.

Ghursheen, Yaqoob, Shah. (2005). Gwadar, Sahi-e-Baluchistan, Quetta: Mazi, Hal, Mustaqbal, Kalat Builders.

Hill, J. R. (1986). Maritime Strategy for Medium Powers, Maryland: Naval Institute press. Hill, Richard. (1995). “Do We Need a New Definition of Medium Maritime Power?”

\footnotetext{
i Express Tribune. Retrieved 21 June 2016, http://indianexpress.com/article/india/india-newsindia/pakistan-hands-over-2000-acres-to-china-in-gwadar-port-city


costs and trade", World Bank Economic Review, (Vol. 15), Iss. 3, P: 451.

iii http://www.skyscrapercity.com/showthread.php?t=392948 (August, 2013)
} 
${ }^{\text {iv }}$ http://www.google.com (January, 2013)

${ }^{v}$ Dubai Ports Authority, http://www.dpa.co.ae (October, 2013)

${ }^{v i}$ Salalah Port, http://www.salalahport.com (November, 2013)

${ }^{\text {vii }}$ Maiden, Andrew. (March 2003).“Oman Benefits from calm waters,” Middle East,( Iss, 332), P, 42.

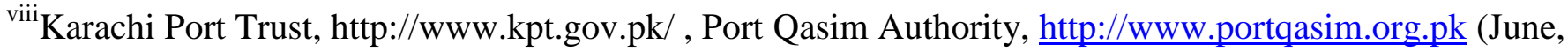
2013)

${ }^{\text {ix }}$ official websites of all above ports

x President of Pakistan's Address at the Ground-Breaking Ceremony of Gwadar Deep-Sea Port, (March 22, 2002), http://www.infopak.gov.pk/CE_Addresses/ce_gwadar.htm

(December, 2013)

${ }^{x i}$ Y. Daniel Coulter, “The Rise of Hub Ports," in Sam J. Tangredi, p. 133.

${ }^{\text {xii }}$ Frankel, J. and Romer, D., “Does Trade Causes Growth?” American Economic Review,89, June 1999, pp. 379-99.

xiii Op, cit

${ }^{\text {xiv }} \mathrm{Op}$, cit

${ }^{\mathrm{xv}}$ http://www.gwadarport.gov.pk (October, 2013)

${ }^{\mathrm{xvi}}$ http://hdl.handle.net/10945/2138 (October, 2013) 